\title{
Management of syncope: from evidence to clinical practice
}

\author{
Tiziana M. Attardo, ${ }^{1}$ Immacolata Ambrosino, ${ }^{2}$ Elena Magnani, ${ }^{3}$ Nathan Artom,${ }^{4}$ Nicola Battino,${ }^{5}$ Deasy Cervo, ${ }^{6}$ \\ Massimiliano Chiuch, ${ }^{7}$ Mariella Frualdo, ${ }^{8}$ Miriam Gino, ${ }^{9}$ Federico Pasin, ${ }^{10}$ Carlo Zaninetti ${ }^{11}$ \\ ${ }^{1}$ Department of Internal Medicine, Barone Lombardo Hospital, Canicattì (AG); ${ }^{2}$ Department of Geriatrics, Hospital of Foggia; \\ ${ }^{3}$ Department of Internal Medicine, M. Bufalini Hospital, Cesena (FC); ${ }^{4}$ Clinic of Internal Medicine 1, San Martino University \\ Hospital, University of Genova; ${ }^{5}$ Department of Internal Medicine and Hemocoagulopathies, University Hospital of Monserrato, \\ Cagliari; ${ }^{6}$ Department of Internal Medicine and High Complexity Care, Careggi Hospital, Firenze; ${ }^{7}$ Clinic of Internal Medicine, \\ Hospital of Trieste, Trieste; ${ }^{8}$ Department of Internal Medicine 4, Molinette Hospital, University of Torino; ${ }^{9}$ Department of \\ Internal Medicine, Ospedale degli Infermi, Rivoli (TO); ${ }^{10}$ Department of General Medicine, Hospital of Cremona, Oglio-Po (CR); \\ ${ }^{11}$ Department of Internal Medicine III, San Matteo Polyclinic and Scientific Research Foundation, University of Pavia, Italy
}

\begin{abstract}
Syncope is defined as a transient loss of consciousness due to temporary global cerebral hypoperfusion. It is characterized by rapid onset, short duration, loss of postural tone possibly causing patient fall, and spontaneous full recovery. Syncope has a high prevalence and incidence within the general population with a relevant impact on both quality of life and health care costs. The diagnosis of syncope is often inaccurate and subject to delay, and management is greatly variable. The main objective of this monograph is to discuss a methodological diagnostic approach to signs and symptoms suggestive of syncope, aiming for a management optimization. The present work is based on a systematic review of recent international guidelines.
\end{abstract}

\section{Introduction}

Syncope is defined as a transient loss of consciousness (T-LOC) due to temporary global cerebral hypoperfusion. It is characterized by rapid onset, short duration, spontaneous full recovery and loss of postural tone, possibly causing patient fall. The post-syncopal recovery phase is typically rapid, although a retrograde amnesia can occur. The diagnosis of syncope is often inaccurate and its management is greatly variable, ${ }^{1}$ while a correct diagnosis and risk stratification are crucial for patients' outcomes. ${ }^{2}$

The main objective of this monograph is to discuss the recommendations from international guidelines/

Correspondence: Tiziana M. Attardo, UO di Medicina Interna, Ospedale Barone Lombardo di Canicattì, Asp 1, via Senatore Sammartino 12, 92024 Canicattì (AG), Italy.

Fax: $+39.0922 .733395 / 830125$.

E-mail: claudia.fantucchio@alice.it

Key words: Syncope; transient loss of consciousness; unexplained syncope; internal loop recorder.

Received for publication: 15 April 2016. Accepted for publication: 27 April 2016.

This work is licensed under a Creative Commons Attribution NonCommercial 4.0 License (CC BY-NC 4.0).

(C) Copyright T.M. Attardo et al., 2017

Licensee PAGEPress, Italy

Italian Journal of Medicine 2017; 11:23-36

doi:10.4081/itjm.2016.732 guidance focusing on diagnosis and optimization of resources.

\section{Epidemiology}

Syncope is a frequent condition, reaching two peaks of incidence within the general population: one between 15 and 30 years and a second in patients aged 70 years or older. ${ }^{3}$ Cohort and population studies demonstrated that about $40 \%$ of the adult population experience a T-LOC once in a life-time (sometimes described as a weakness or a black-out), with a higher incidence among women. ${ }^{3}$ The increased incidence in older individuals is explained by the increased use of vasoactive drugs and the higher prevalence of arrhythmias. ${ }^{3}$ Several disorders may resemble syncope and occur with either a complete or an apparent loss of consciousness, ${ }^{3}$ but they do not recognize an underlying global cerebral hypoperfusion mechanism. With regard to the first group, the mechanism is other than global cerebral hypoperfusion: examples are epilepsy, metabolic disorders (including hypoxia and hypoglycemia), intoxication, and vertebrobasilar transient ischemic attack. The other group includes cataplexy, drop attacks, falls and the so-called psychogenic pseudosyncope (Figure 1). ${ }^{2}$

Syncope accounts for up to $1-3 \%$ of hospital admissions and Emergency Deparment (ED) visits and in these settings, it is associated with cardiovascular co-morbidity and cardiovascular pharmacotherapy. In older adults, syncope is a major cause of morbidity and mortality with enormous personal and wider 
health economic costs. ${ }^{3}$ The main causes of access to the ED for syncope patients are trauma (minor injuries around $29 \%$ of cases and more to $4.7 \%$ ) and carotid sinus hypersensitivity. ${ }^{3}$

\section{Etiology and pathogenesis of syncope}

The acute approach to a patient with syncope consists of carefully collecting personal medical history (directly from the patient or from a person who was with him/her when the syncope occurred) and an accurate physical examination for an initial differential diagnosis. Syncope recognizes different causes: however, those are identifiable in no more than two thirds of patients. Table $1^{2}$ summarizes the causes of syncope.

\begin{abstract}
ABC syncope
The initial evaluation of a patient presenting with T-LOC should answer to three key questions: i) Is it a syncopal episode or not? ii) Is the etiological diagnosis determined? iii) Is the patient at a high risk for cardiovascular events or death?
\end{abstract}

\section{Is it a syncopal episode or not?}

The differentiation between syncope and non-syn- copal conditions with real or apparent LOC can be achieved with a detailed clinical history, although is often challenging. The following questions should be answered: i) Was LOC complete? ii) Was LOC transient with rapid onset and short duration? iii) Did the patient lose postural tone?

If we have positive answers, it is very likely that the episode is syncope. If we have negative answer to one or more of these questions, we must exclude other forms of LOC and then we proceed with syncope evaluation. ${ }^{2}$

\section{Is the etiological diagnosis defined?}

The milestones of initial evaluation of a patient presenting with syncope are three (Table 2): ${ }^{2}$

- Patient medical history, what to ask: i) circumstances just prior to syncope: position, activity, predisposing factors; ii) syncope onset: nausea, vomiting, palpitations; iii) characteristics: way of falling, skin color, duration of loss of consciousness, breathing pattern, tongue bite, movements-type, duration, onset in relation to fall); iv) syncope end: nausea, vomiting, sweating, feeling of cold, confusion, muscle aches, skin color, injury, chest pain, palpitations, urinary or fecal incontinence; v) background: family history of sudden death, previous cardiac disease, neurological history, metabolic disorders, medication, information

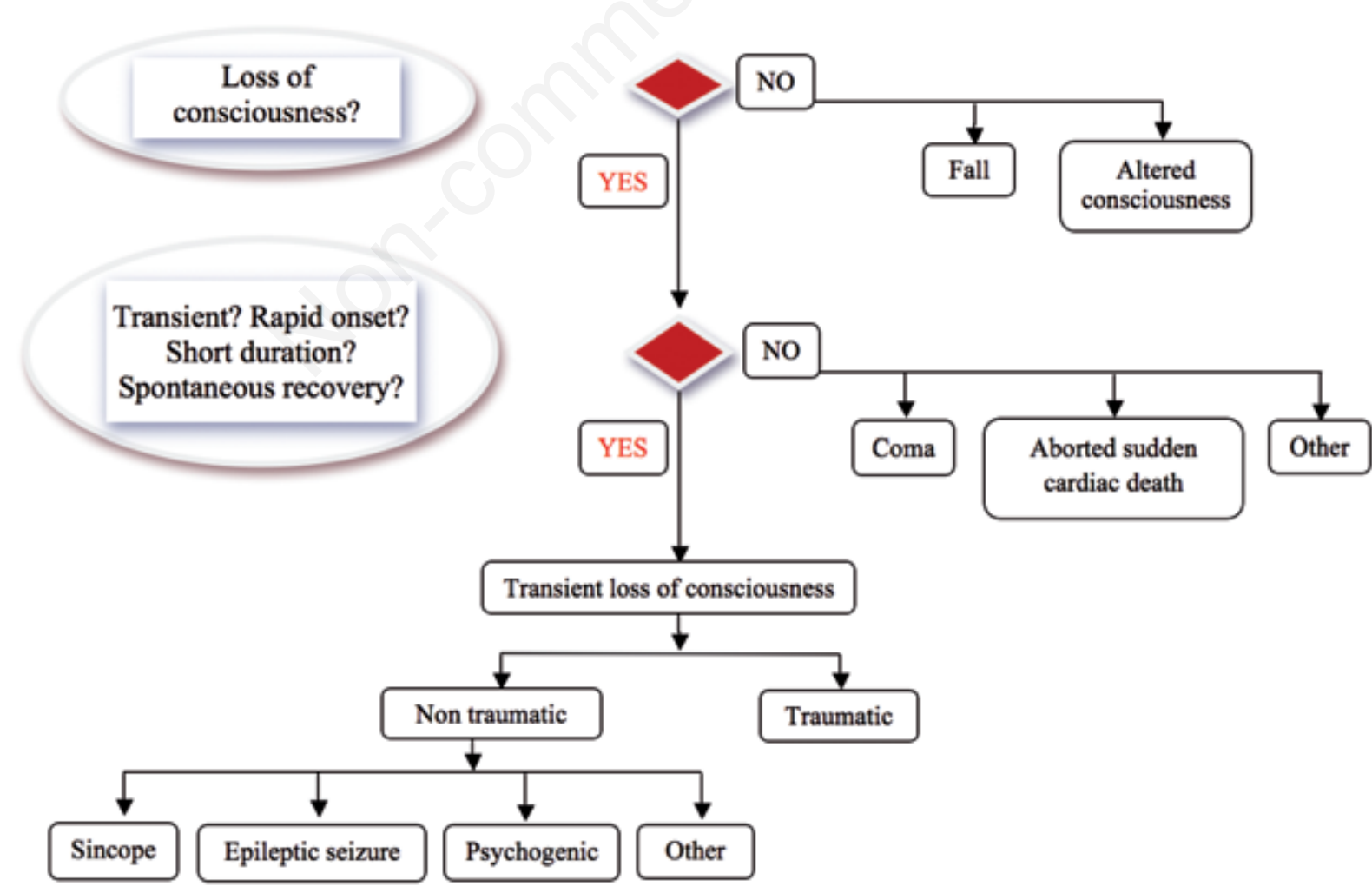

Figure 1. Type of loss of consciousness (LOC). Modified from The Task Force for the Diagnosis and Management of Syncope of the European Society of Cardiology (ESC), 2009. ${ }^{2}$ 
on recurrences such as the time from the first syncopal episode and on the number of spells (in the case of recurrent syncope).

- Physical examination: in the initial evaluation, the physical examination would better include the orthostatic challenge assessment when there is a suspicion of a reflex mechanism of orthostatic hypotension $(\mathrm{OH})$.

- The electrocardiogram (ECG) is essential both for etiological diagnosis and for risk stratification.

\section{Is the patient at a high risk for cardiovascular events or death?}

The third phase of the initial evaluation of syncope is focused on the risk assessment to determine the pressing need for hospitalization or intensive care.
Table $3^{2}$ summarizes a classification of high-risk criteria for hospitalization and/or intensive evaluation. Patients with a single major risk factor must receive an urgent cardiac assessment, while patients with one or more minor risk factors could be considered for receiving an urgent cardiac assessment.

Major risk factors are: i) abnormal ECG (any bradyarrhythmia, tachyarrhythmia or conduction disease, new ischemia or old infarct); ii) history of cardiac disease; iii) hypotension; iv) heart failure (either past history or current state).

Minor risk factors are: i) age $>60$; ii) dyspnea; iii) anemia; iv) cerebrovascular disease; v) family history of early sudden death; vi) specific situations, such as syncope while supine, during exercise, or with no prodromal symptoms.

Table 1. Classification of syncope.

Cardiac and cardiovascular syncope

Arrhythmia as primary cause

Bradycardia:

Sinus node dysfunction (including bradycardia/tachycardia syndrome)

Atrioventricular conduction system disease

Implanted device malfunction

Tachycardia:

Supraventricular

Ventricular (idiopathic or secondary to structural heart disease or to channelopathies)

Drug induced bradycardia and tachyarrhythmias

Structural disease

Cardiac:

Cardiac valvular disease, myocardial infarction, hypertrophic cardiomyopathy, cardiac masses (atrial myxoma, tumors, etc.), pericardial disease/tamponade, congenital anomalies of coronary arteries, prosthetic valves dysfunction

Others:

Pulmonary embolus, aortic dissection, pulmonary hypertension

\section{Reflex syncope}

Vasovagal:

Mediated by emotional distress: fear, pain, instrumentation, blood phobia

Mediated by orthostatic stress

Situational:

Cough, sneeze

Gastrointestinal stimulation: swallow, defecation, visceral pain

Micturition, post-micturition

Post-exercise

Post-prandial

Others (laugh, brass instrument playing, weightlifting)

Carotid sinus syndrome

Atypical forms (without apparent triggers and/or atypical presentation)

\section{Syncope due to orthostatic hypotension (autonomic failure)}

Primary autonomic failure:

Pure autonomic failure, multiple system atrophy, Parkinson's disease, Lewy body dementia, idiopathic orthostatic hypotension

Secondary autonomic failure:

Diabetes, amyloidosis, terminal uraemia, spinal cord injuries

Drug-induced orthostatic hypotension:

Alcohol, vasodilators, diuretics, phenotiazines, antidepressants

Volume depletion:

Hemorrhage, diarrhea, vomiting, etc.

Modified from The Task Force for the Diagnosis and Management of Syncope of the European Society of Cardiology (ESC), 2009. ${ }^{2}$ 


\section{Diagnostic approach to cardiogenic syncope}

\section{Electrocardiogram}

The gold standard for the diagnosis of syncope is represented by the demonstration of likely causality between symptoms and underlying mechanism, in particular arrhythmia. ${ }^{2}$

There are different lengths and types of ECG analysis in front to a suspicion of etiology of syncope, the individual risk level and the expected rate of recurrent syncope. ${ }^{4}$

In-hospital ECG monitoring (in bed or telemetry) should be undertaken in any patient with high-risk of arrhythmic etiology. Holter monitoring is appropriate in patients who have frequent episodes ( $\geq 1$ per week). Implantable loop recorder (ILR) is mainly indicated in patients without high risk but an arrhythmic suspicion of the syncope. External loop recorder is an alternative to ILR when symptoms occur at a rate of $>2$ /month

\section{Echocardiography}

Echocardiography represents an important technique to evaluate the presence of structural and functional cardiac disease involved in the etiology of cardiogenic syncope and it identifies the risk stratification. ${ }^{2}$ The detectable conditions are: aortic stenosis, tumors or thrombi causing cardiac obstruction, pericardial tamponade, aortic dissection, congenital abnormalities of coronary arteries. Echocardiography plays also a role in hemodynamically unstable patients suspected with pulmonary embolism for whom a computed tomography pulmonary angiography is not immediately available.

\section{Electrophysiological study}

Electrophysiological study (EPS) is actually limited to a study of suspect arrhythmic syncope in patients with ischemic heart disease, ${ }^{2}$ in order to assess the exact underlying mechanism (syncope in the pres-

Table 2. Clinical features that may suggest the diagnosis at the time of the initial assessment.

\section{Neurally mediated syncope}

- Absence of heart disease

- Long history of recurrent syncope

- After sudden unexpected unpleasant sight, sound, smell or pain

- Prolonged standing or crowded, hot places

- Nausea and vomiting associated with syncope

- During a meal or post-prandial

- With head rotation or pressure on carotid sinus (as in tumors, shaving, tight collars)

- After exertion

\section{Syncope due to orthostatic hypotension}

- After standing up

- Temporal relationship with start or changes of dosage of vasodepressive drugs leading to hypotension

- Prolonged standing especially in crowded or hot places

- Presence of autonomic neuropathy or Parkinsonism

- Standing after exertion

\section{Cardiovascular syncope}

- Presence of definite structural heart disease

- Family history of unexplained sudden death or channelopathy

- During exertion or supine

- Abnormal ECG

- Sudden onset palpitation immediately followed by syncope

- ECG findings suggesting arrhythmic syncope

- Bifascicular block (LBBB o RBBB + LAH/LPH)

- Other intraventricular conduction abnormalities (QRS duration $>120 \mathrm{~ms}$ )

- Mobitz 1 second degree AV block

- Asymptomatic inappropriate sinus bradycardia $(<50 \mathrm{bpm})$, sinoatrial block or sinus pause $\geq 3$ " in the absence of negatively chronotropic medications

- Non sustained ventricular tachycardia

- Ventricular pre-excited

- Long or short QT intervals

- Early repolarization

- Right bundle branch block pattern with ST elevation in leads V1-V3 (Brugada syndrome)

- Negative T waves suggesting myocardial infarction

- Negative T waves in right precordial leads, epsilon waves and ventricular late potentials suggestive of arrhythmogenic right ventricular cardiomyopathy

ECG, electrocardiogram; LBBB, left bundle branch block; RBBB, right bundle branch block; LAH/LPH, left anterior hemiblock/left posterior hemiblock; AV, artrial ventricle. Modified from The Task Force for the Diagnosis and Management of Syncope of the European Society of Cardiology (ESC), 2009. ${ }^{2}$ 
ence of prolonged sinus bradycardia, bundle branch block, supraventricular tachycardia, sustained monomorphic tachycardia). ${ }^{2}$ The EPS is functional to agree a specific treatment as the implantable cardioverter defibrillator (ICD) implantation or catheter ablation procedure. However, in case of severely depressed left ventricular ejection fraction (EF) the ICD should be yet indicated regardless the mechanism of syncope. Furthermore, more sensitive and non-invasive procedures are preferable to detect the syncope mechanism as the ECG continuous and ILR.

\section{Exercise stress testing}

Exercise testing is indicated in patients who had episodes of syncope during or shortly after exertion. The test is diagnostic if it reproduces syncope with ECG abnormalities or severe hypotension. ${ }^{2}$

\section{Diagnostic approach to non-cardiogenic syncope}

Neurogenic syncope is the most common cause of syncope. Provocative tests are aimed to reproduce the mechanism of syncope or related abnormalities in an artificial setting.

\section{Carotid sinus massage}

In some individuals, the normal carotid sinus baroreceptor reflex is damaged therefore it can be triggered by minor stimuli, causing an abnormal response of the blood pressure and heart rate controls, leading to neurally mediated syncope or symptoms related. The carotid massage is a simple test that it is able to reproduce this disorder. Carotid sinus hypersensitivity is diagnosed when carotid sinus massage (CSM) causes a $>3 \mathrm{~s}$ asystole and/or lowering of the systolic blood pressure $>50 \mathrm{mmHg} .{ }^{2}$ Carotid sinus syndrome is defined when syncopal symptoms accompany these heart frequency or blood pressure changes. The massage consists in a manual light phasic rubbing lasting ten seconds on the right and on the left sides, both in supine and erect position, throughout continuous monitoring of heart rate and blood pressure. In about 30\% of patients an abnormal response is present only in orthostatic position. ${ }^{2}$ Carotid sinus hypersensitivity is quite common in older men and carotid sinus syndrome is exceptional in patients less than forty years old. In fact, after initial evaluation CSM should be performed in all patients with unexplained syncope aged $>40$ years. CSM is contraindicated in patients who have sustained a myocardial infarction in the last 3 months and in the presence of carotid bruits (unless Doppler studies have shown no significant arterial stenosis). ${ }^{2}$ A panel of experts proposed a CSM cut-off change, in particular to consider positive a massage for asystole $\geq 6 \mathrm{~s}$ and drop in the mean blood pressure $\geq 60$ lasting for $\geq 6$ s. $^{5}$

\section{Orthostatic hypotension}

The active orthostatic test is used to diagnose different types of orthostatic intolerance. ${ }^{2}$ The classical

Table 3. Classification of high risk criteria for hospitalization and/or intensive evaluation.

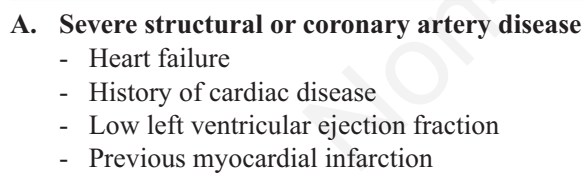

B. Clinical or electrocardiogram features suggesting arrhythmic syncope

- Syncope during exertion or supine

- Palpitations at the time of syncope

- Family history of sudden cardiac death

- Non-sustained ventricular tachycardia

- Bifascicular-block: left bundle branch block or right bundle branch block (RBBB) combined with left anterior or left posterior fascicular block; other intraventricular conduction abnormalities with QRS duration $>0=120 \mathrm{~ms}$

- Inadequate sinus bradycardia $(<50 \mathrm{bpm})$ or sinoatrial block in absence of negative chronotropic medications or physical training

- Pre-excited QRS complex

- Prolonged or short QT interval

- RBBB pattern with ST-elevation in leads V1-V3 (Brugada pattern) Negative T waves in right precordial leads, epsilon waves, and ventricular late potentials suggestive of arrhythmogenic right ventricular cardiomyopathy

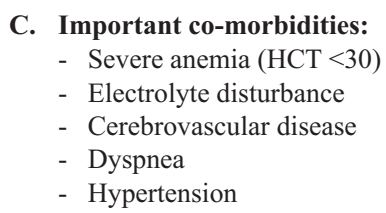

Modified from The Task Force for the Diagnosis and Management of Syncope of the European Society of Cardiology (ESC), 2009. ${ }^{2}$ 
$\mathrm{OH}$ is the most frequent form. In fact, the test is usually indicated in patients with syncope or dizziness that occur in the first $3 \mathrm{~min}$ of adopting erect position. Orthostatic hypotension is evaluated with manual intermittent blood pressure measurement with sphygmomanometer lying-to standing for at least $3 \mathrm{~min}$; the diagnosis of $\mathrm{OH}$ is made if there is a symptomatic fall in systolic blood pressure (BP) from baseline value $\geq 20 \mathrm{mmHg}$ or a decrease in diastolic $\mathrm{BP} \geq 10 \mathrm{mmHg}$, as well as a decrease in systolic BP to $<90 \mathrm{mmHg}$. If the test is doubtful, it is indicated the blood pressure continuous monitoring. ${ }^{2}$

\section{Tilt table test}

Tilt testing is a tool to reproduce a neurally mediated reflex triggered by prolonged standing and it shows an impaired vasoconstriction capability that can provoke a reflex syncope. The primary indications of this test are recurrent syncopes in the absence of organic heart disease or a single unexplained episode in high-risk settings. Nitroglycerine protocol is the useful tilt testing method. The response is a vasovagal reaction vasodepressive, cardioinhibitory, and mixed. ${ }^{2}$

\section{Diagnostic approach to unexplained syncope}

\section{Loop recorder}

Despite a complete and comprehensive diagnostic approach, approximately $30 \%$ of patients with T-LOC does not reach a conclusive diagnosis: in this case, it is defined as syncope unexplained suitably. ${ }^{6}$ The ILR is a small device for subcutaneous implantation with retrospective memory able to retain the ECG trace for prolonged periods of time and with very prolonged duration memory (even more years). Generally, this device weighing about $17 \mathrm{~g}$ is positioned in the anterior chest wall in a pocket similar to the common pacemaker. Initially the ILR was used in patients with unexplained syncope at the end of a complete but unsuccessful diagnostic workup. Based on the first experiences, it became clear the ILR is a useful diagnostic tool when the arrhythmic cause of syncope is suspected but not proven with certainty from the usual diagnostic approach.

Patients' selection for the ILR-study is based on careful risk stratification and resulting pre-test probability to identify a syncopal-related arrhythmia. Relapse's rate and syncopal events' recurrence (that is to say number of T-LOC per year) and ECG-graphics alterations, such as a bundle branch block, have a high positive predictive value regarding on syncope incidence, so there are useful factors for patients' selection. ${ }^{7}$ Conversely age, sex, positive response to the tilt test and presentation's severity of loss of consciousness have a low predictive value. ${ }^{8}$ The ILR is a valu- able weapon for the definitive diagnosis of syncope; it can be used in patients with block bundle where it is highly able to document a paroxysmal atrial ventricular (AV) block, in patients with structural heart disease but with negative cardiac evaluation, in individuals with documented carotid sinus hypersensitivity, in pediatric patients, or in patients with probable neurally mediated syncope diagnosis after initial assessment. Because of various recent evidence, the ILR appeared useful in differential diagnosis between syncope and T-LOC seizure in patients with epilepsy diagnosis that have not benefit from antiepileptic treatment, in patients with major depressive syndrome with frequent episodes of unexplained syncope, or in older individuals with recurrent unexplained falls. ${ }^{9-11}$ Based on the results of trials conducted about unexplained syncope and use of ILR (ISSUE 1 and 2, PICTURE, EVISE and others), it is clear the high diagnostic value of the ILR to correlate the unexplained syncopal event and arrhythmia, to obtain a definitive diagnosis and to promote a decisive therapy. ${ }^{12,13}$ For this reason, the ILR implant over time indication will be incremented in about 34 cases per million inhabitants per year compared to current use. ${ }^{14,15}$ The question about the ILR implantation proper timing remains open entirely; if this device was initially considered a last resort option and reserve diagnostic once other investigative weapons were exhausted, now various evidence indicates a potential role of this early. ${ }^{7}$ In conclusion, according to the European Society of Cardiology (ESC) 2009 guidelines the ILR implantation is indicated with Class 1 and evidence A: i) in patients with recurrent and uncertain origin syncope after initial assessment to exclude high risk factors presence such as severe structural heart disease and coronary important comorbidities, family history of sudden cardiac death, inadequate sinus bradycardia, BBB, abnormal QT or ventricular repolarization, preceded by palpitations or syncope occurred in the supine position or even during exercise in early stage; ii) in patients with both high likelihood of syncope recurrence (at least three syncopal episodes in the previous two years with interval between the first and the last event of at least 6 months) within the operating time of the device's battery; iii) in high-risk patients in whom complete evaluation has not led to diagnosis or did not lead to specific treatment.

The ILR diagnostic tool can also be used: i) in patients with certain or suspected neurally mediated syncope, frequent or unpredictable risk of trauma, in order to identify the role of bradycardia before a pacemaker implantation; ii) in patients with T-LOC in order to exclude the arrhythmic genesis safely.

The ECG finding provided by ILR is diagnostic when it is demonstrated the correlation between syncope and arrhythmia or in case of BAV II or III or in 
case of a ventricular pause greater than $3 \mathrm{~s}$, or in case of above-ventricular paroxysmal tachycardia and rapid ventricular rhythm. Conversely, the finding ECG provided by ILR allows excluding an arrhythmic cause when there is no correlation between syncope and changes in heart rate. Finally, the ILR should be continued in case of pre-syncope, in case of asymptomatic arrhythmias or sinus bradycardia. The economic impact of the ILR for each diagnosis is lower than conventional diagnostic; it could appear superior only if it is taken individually and in the initial phase; in other words, the performance and the guaranteed rate of diagnostic efficacy compensate the high initial cost. ${ }^{16,17}$ In conclusion, the use of ILR in selected patients remains an accurate although expensive, effective and valuable tool for the diagnosis and management of patients with recurrent unexplained syncope. Unlike many conventional monitoring available methods, the ILR provides both a high yield valuable diagnostic information and risk stratification in a single test. Based on the current evidence-based guidelines, the use of ILR should be considered an accurate and effective tool for the management of patients with syncope, but it does not replace a detailed initial assessment characterized by a careful history and a meticulous physical examination.

\section{Neurological and psychiatric evaluations}

The Neurologist is consulted for differential diagnosis both syncope and epilepsy, or to define autonomic failure in the context of neurologic ill patient. Electroencephalogram and brain scan are not recommended in the syncope study flow chart however in the differential diagnosis of other T-LOC psychiatric evaluation should be performed for a suspicion of functional attacks (pseudo-epilepsy and pseudo-syncope).

Finally, it is important to remind the concurrent multiple causes underlying a single syncopal episode, especially in the elderly population.

\section{Therapy}

The treatment of patients with syncope has the main goal to prolong survival, limit physical injuries and prevent recurrence. ${ }^{2}$ It must be directed to the causes, which underlie the temporary global cerebral hypoperfusion $^{2}$ so it is very essential the risk stratification and the identification of specific mechanism (Figure 2). ${ }^{2}$

Recent guidelines on cardiac pacing ${ }^{18}$ underline that bradyarrhythmias requiring cardiac pacing can have different etiologies and that the early identification of a potentially reversible cause represents the first step towards efficacious treatment. When a transient or reversible cause is excluded, the indication for cardiac pacing is determined by the severity of bradycardia, in particular we can recognize a persistent bradycardia, which is caused by an intrinsic disease of the sinus node or AV conduction system, and an intermittent bradycardia, whose etiology is more difficult to determine (Figure 3). ${ }^{18}$

\section{Orthostatic hypotension}

Lifestyle advices can improve orthostatic symptoms markedly, even if the rise in blood pressure is relatively small (10-15 $\mathrm{mmHg}$ ). An important goal is the expansion of extracellular volume, in fact patients without hypertension should be instructed to take sufficient salt and water intake, such as 2-3 L of fluids per day and $10 \mathrm{~g}$ of $\mathrm{NaCl}^{19}{ }^{19}$ Physical counter pressure maneuvers such as leg crossing and squatting may be indicated (Class II b, Level C). ${ }^{20}$ In older patients, abdominal binders and/or support stockings to reduce venous pooling may be indicated (Class IIb, Level C). ${ }^{21,22}$ Midodrine should be administered as adjunctive therapy if needed (Class IIa, Level B), such as Fludrocortisone (Class IIa, Level C). ${ }^{2}$

\section{Syncope secondary to structural cardiac or cardiovascular disease}

In patients with syncope secondary to structural cardiac disease, including congenital heart malformations or cardiopulmonary disease, treatments have to aim not only to prevent syncopal recurrence, but also to treat the underlying disease and to decrease the risk of sudden cardiac death (SCD). ${ }^{2}$

There is some evidence ${ }^{23-27}$ supporting both shortand long-term benefits of resynchronization therapy (CRT) in patients in sinus rhythm with the New York Heart Association (NYHA) class III; moreover, CRT improves left ventricular function, decrease mortality and hospitalization rate in patients in sinus rhythm with NYHA class I and II. ${ }^{28-31}$

In particular in patients in sinus rhythm with: i) left bundle branch block (LBBB) and QRS duration $>150$ $\mathrm{ms}$, CRT is recommended in chronic heart failure patients, left ventricular EF (LVEF) $\leq 35 \%$ and in those who remain in NYHA class II, III and IV despite adequate medical treatment (Class I, Level A); ii) LBBB and QRS duration 120-150 ms, CRT is recommended in chronic heart failure patients, $\mathrm{LVEF} \leq 35 \%$ and in those who remain in NYHA class II, III and IV despite adequate medical treatment (Class I, Level B); iii) absence of LBBB and QRS duration $>150 \mathrm{~ms}$, CRT should be considered in chronic heart failure patients, LVEF $\leq 35 \%$ and in those who remain in NYHA class II, III and IV despite adequate medical treatment (Class IIa, Level B); iv) absence of LBBB and QRS duration 120-150 ms, CRT may be considered in chronic heart failure patients, $\mathrm{LVEF} \leq 35 \%$ and in those who remain in NYHA class II, III and IV despite adequate medical 
treatment (Class IIb, Level B); v) CRT is not recommended in patients with chronic heart failure and QRS duration $<120 \mathrm{~ms}$ (Class III, Level B). ${ }^{18}$

Biventricular pacing (BiV) is used in CRT mainly. ${ }^{18}$

On the other hand in patients with atrial fibrillation we have the following conditions: i) CRT should be considered in chronic heart failure patients, intrinsic QRS duration $\geq 120 \mathrm{~ms}$ and $\mathrm{LVEF} \leq 35 \%$ and in those who remain in NYHA class III and IV despite adequate medical treatment (Class IIa, Level B); ii) AV junction ablation should be used in case of incomplete BiV pacing in patients with chronic heart failure, long QRS and reduced LVEF (Class IIa, level B); iii) fi- nally CRT should be considered in patients with reduced LVEF who are candidates for AV junction ablation for rate control. ${ }^{18}$

When an ICD is indicated in primary or secondary prevention of sudden death, it is recommended that CRT is added to improve symptoms, exercise tolerance and cardiac function and to reduce hospitalization in symptomatic patients with chronic heart failure with adequate medical treatment, $\mathrm{LVEF} \leq 35 \%$ e complete LBBB (Class I, Level A). 26,28,30,31

Cardiac resynchronization therapy and defibrillator is used in the presence of the following factors: i) life expectancy $>1$ years; ii) stable heart failure (Class

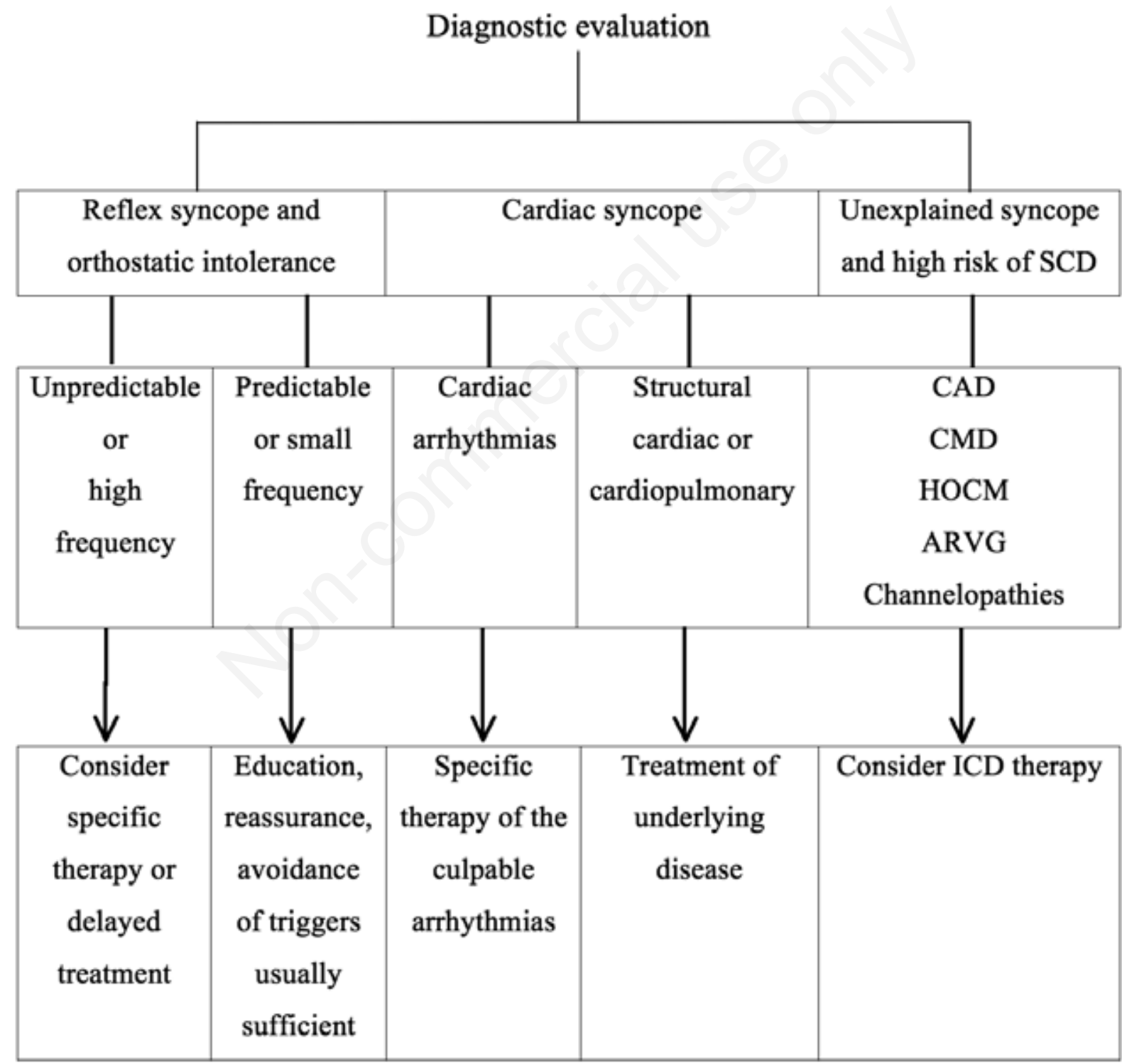

Figure 2. Recommendation to treatment of syncope based on etiopathogenic definition. SCD, sudden cardiac death; CAD, coronary artery disease; CMD, dilated cardiomyopathy; HOCM, hypertrophic obstructive cardiomyopathy; ARVG, arrhythmogenic right ventricular cardiomyopathy; ICD, implantable cardioverter defibrillator. Modified from The Task Force for the Diagnosis and Management of Syncope of the European Society of Cardiology (ESC), 2009. ${ }^{2}$ 
NYHA II); iii) ischemic heart disease and lack of comorbidities. ${ }^{18}$

On the other hand, cardiac resynchronization therapy and pacemaker is indicated in the presence of: i) advanced heart failure; ii) severe renal insufficiency or dialysis; iii) other major comorbidities; iv) frailty and cachexia.

\section{Unexplained syncope in patients with high risk of sudden cardiac death}

In patients at high risk of SCD it is required a specific treatment to reduce risk of mortality and of minacious events. ${ }^{2}$ Unexplained syncope is a major risk factor for SCD in patients with hypertrophic cardiomyopathy; in these patients in whom symptoms can be caused by left ventricular outflow tract obstruction, treatment options include: negative inotropic drugs, surgical operation (septal myectomy), septal alcohol ablation and sequential AV pacing. ${ }^{18}$ In particular sequential AV pacing with short AV interval may be considered in selected patients with left ventricular outflow tract obstruction and drug-refractory symptoms who have contraindications for septal alcohol ablation or septal myectomy (Class IIb Level B) or who are at high risk of developing heart block during septal alcohol ablation or septal myectomy (Class IIb, Level C). In conclusion for patients in whom there is an indication for ICD, a dual-chamber ICD should be considered.

\section{The management of patient with syncope: rationale and objective}

The main objective of this monograph is to define a methodological approach to the single symptom, raising awareness to the clinical management of the same in the different clinical presentations and/or in different patients, even by means of score of gravity.

\section{The management of syncope: methodology}

In order to provide evidence-based recommendations for the management of patients with syncope, we

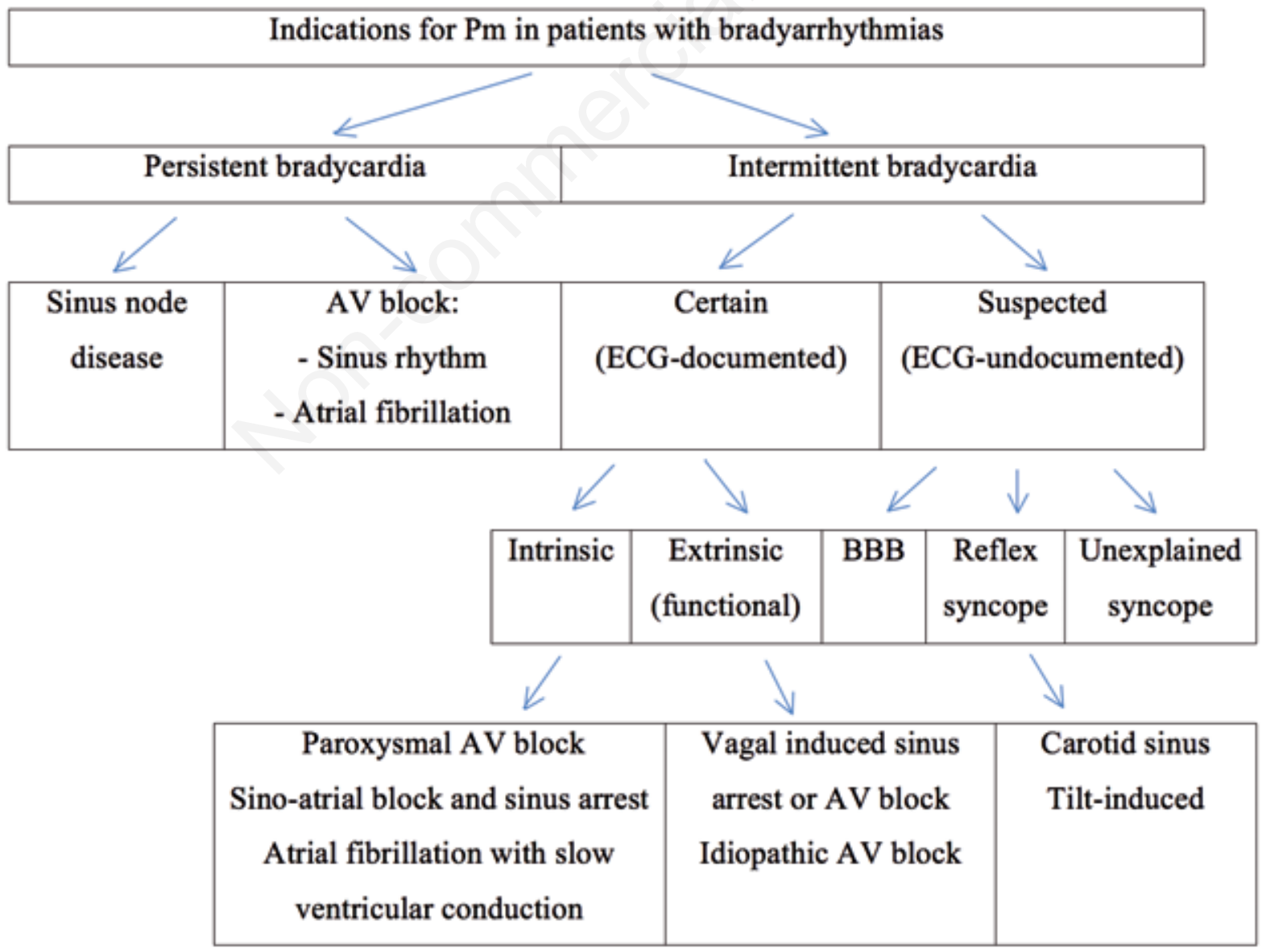

Figure 3. Classification of bradyarrhythmias based on the patient's clinical presentation. Pm, pacemaker; AV, atrioventricular; ECG, electrocardiogram; BBB, bundle branch block. Modified from Brignole and Auricchio, $2013 .{ }^{18}$ 
first verified the existence of guidelines on the topic. A systematic review of syncope-focused guidelines was performed accessing Medline via PubMed and the following guidelines-focused databases:

- Scottish Intercollegiate Guidelines Network (SIGN);

- Institute for Clinical Systems Improvement (ICSI);

- National Institute for Health and Care Excellence (NICE) (NHS evidence);

- National Guideline Clearinghouse; Canadian Medical Association, CMA Infobase;

- New Zealand Guidelines Group;

- National System Guidelines;

- Clinical Practice Guidelines Portal;

- eGuidelines.

The research was carried out by twelve authors independently, using the term syncope as key-word when the site included the search function, and in other cases we listed the last guidelines manually stored in the database or made reference to cardiovascular, from 2006 until 2013. The Medline literature strategy is available upon request. The inclusion process involved a two-step phase and a quality assessment. The results obtained separately were compared and discussed together subsequently.

Then obtained guidelines were evaluated using the AGREE instrument (Appraisal of Guidelines, Research and Evaluation II) ${ }^{32}$ by 11 authors independently, in order to identify the guidelines qualitatively better. AGREE II assesses compliance with 23 requirements, meeting 6 domains as the explanation of the purpose, the clarity, the involvement of all stakeholders, the rigor of development, applicability and editorial independence of the same. Each author assessed the compliance of individual requirements with a score from 1 (disagree completely) to 7 (complete agreement). The scores assigned by each author were added within individual domains and reported with the highest and the lowest possible score within the domain based on the included requirements' and evaluators' number.

In order to update the evidence given by the guidelines, an author conducted a post hoc search of the available evidence in literature from 2009 to 2014 in order to obtain an elaborate updated carried out. He considered randomized controlled trials, meta-analyses and reviews, excluding case reports and case series.

In our post-hoc evaluation, given the vastness of the subject, we schematically divided randomized controlled clinical trials, meta-analyses and reviews analyzed in six different topics which are shown below: i) classification of syncope according to the action's mechanism; ii) use of diagnostic and therapeutic dedicated to syncope software with algorithms to address the work up of syncope to be used in ED; iii) novelties in the physiology of neurogenic syncope; iv) assessment of carotid sinus syndrome; v) signs of pacemaker implant according to 2013 guidelines; vi) pharmacological treatment.

\section{The management of syncope: results}

Through the databases, we identified and selected 8 guidelines for evaluation.

The overall quality of selected guidelines was assessed by 11 authors using the AGREE instrument II. The evaluation results are shown in Table 4., 1,2,4,18,33-37

The Guidelines for the diagnosis and management of syncope (version 2009) - The Task Force for the diagnosis and Management of Syncope of the European Society of Cardiology (ESC) ${ }^{2}$ was the one which has been assessed by us; it had the greatest overall score, so it was the reference guidelines for the preparation of this monograph. It was judged adoptable in $100 \%$ of cases by the group, but with modifications for an evaluator.

The 2006 AHA/ACCF Scientific Statement on the Evaluation of Syncope ${ }^{33}$ was not considered to be adopted by the group; it had a very low evaluation in the third dimension (12.12\%), which assessed the methodological rigor in scientific research evidence and in their assessment, and in the fifth (16.29\%), which assessed their applicability.

The Guidelines for the diagnosis and management of syncope (version 2009) the National Guidelines Clearinghouse $^{4}$ was also judged adoptable in $100 \%$ of cases by the group, but with changes for three evaluators. It reached high score percentages especially for the first dimension $(90.91 \%)$, the third $(82 \%)$ and the fourth $(86.36 \%)$; it showed a clear expression of goals and motivations, very good methodological rigor and application.

The 2012 Guideline Standardized Reporting Guidelines for Emergency Department Syncope Risk Stratification Research ${ }^{34}$ was judged not to beeasily applicable in clinical practice.

The 2012 guideline New Concepts in the Assessment of Syncope by Brignole and Hamdan, ${ }^{35}$ was evaluated non-adoptable in $55 \%$ of the evaluators. In detail the guideline in question had low scores in all dimensions.

The guideline Transient loss of consciousness (blackouts) in adults and young people ${ }^{1}$ of NICE was evaluated adoptable by all evaluators (in one case with amendments), except for one. This guideline scored high percentages in all sizes and was characterized by indulging in a particular manner the point of view of the patient who had experiences of T-LOC. In fact, the guideline emphasized that the treatment and care should take on the basis of needs and preferences of patients and that people who experienced T-LOC should be able to make informed 
decisions about their care and treatment with their health operators. It showed particular attention to the need of good communication between health professionals and patients, especially when it was referred to people with physical, sensory or learning disabilities.

The guideline Standardized Approaches to the Investigation of Syncope of Canadian Cardiovascular
Society Position Paper of $2011^{36}$ was evaluated unadoptable by $8 / 11$ evaluators and adoptable only with modifications by the other three. The guideline scored low score percentages in all dimensions $(<$ or around $50 \%$ ), except for the first dimension where it reached $66.7 \%$.

The guideline The Emergency Department approach to Syncope: Evidence - based Guidelines and

Table 4. Summary of the scores of evaluators selected on the syncope guidelines for the different sizes according to the AGREE instrument II.

\begin{tabular}{|c|c|c|c|c|c|c|c|}
\hline Guidelines & $\begin{array}{l}\text { Dimension } 1 \\
\text { Goals and } \\
\text { motivations } \\
\text { Total score } \\
\text { and } \\
\text { percentage }\end{array}$ & $\begin{array}{l}\text { Dimension } 2 \\
\text { Stakeholder } \\
\text { involvement } \\
\text { Total score } \\
\text { and } \\
\text { percentage }\end{array}$ & $\begin{array}{c}\text { Dimension } 3 \\
\text { Methodological } \\
\text { rigor } \\
\text { Total score } \\
\text { and } \\
\text { percentage }\end{array}$ & $\begin{array}{l}\text { Dimension } 4 \\
\text { Clarity in } \\
\text { the exposition } \\
\text { Total score } \\
\text { and } \\
\text { percentage }\end{array}$ & $\begin{array}{l}\text { Dimension } 5 \\
\text { Applicability } \\
\text { Total score } \\
\text { and } \\
\text { percentage }\end{array}$ & $\begin{array}{l}\text { Dimension 6 } \\
\text { Editorial } \\
\text { independenc } \\
\text { Total score } \\
\text { and } \\
\text { percentage }\end{array}$ & $\begin{array}{cc}6 & \begin{array}{c}\text { Overall } \\
\text { (adoptable }\end{array} \\
\text { ce } & \text { or not) } \\
\text { Total score } \\
\text { and } \\
\\
\text { percentage }\end{array}$ \\
\hline $\begin{array}{l}\text { AHA/ACCF Scientific } \\
\text { Statement on the Evaluation } \\
\text { of Syncope, } 2006 \\
\text { (American College of }_{\text {Cardiology Foundation) }}^{33}\end{array}$ & $\begin{array}{c}88 / 198 \\
44.44 \%\end{array}$ & $\begin{array}{c}80 / 198 \\
40.40 \%\end{array}$ & $\begin{array}{c}64 / 528 \\
12.12 \%\end{array}$ & $\begin{array}{c}68 / 198 \\
34.34 \%\end{array}$ & $\begin{array}{l}43 / 264 \\
16.29 \%\end{array}$ & $\begin{array}{r}117 / 132 \text { L } \\
88.63 \% \text { o } \\
\end{array}$ & $\begin{array}{c}\text { Unadoptable in } 91 \% \\
\text { of cases (only in one } \\
\text { case adoptable with } \\
\text { modifications) }\end{array}$ \\
\hline $\begin{array}{l}\text { Guidelines for the diagnosis } \\
\text { and management of syncope } \\
\text { (version 2009) }(E S C)^{2}\end{array}$ & $\begin{array}{l}191 / 198 \\
96.16 \%\end{array}$ & $\begin{array}{l}147 / 198 \\
74.24 \%\end{array}$ & $\begin{array}{c}415 / 528 \\
78.60 \%\end{array}$ & $\begin{array}{c}195 / 198 \\
98.5 \%\end{array}$ & $\begin{array}{c}207 / 264 \\
78.41 \%\end{array}$ & $\begin{array}{l}119 / 132 \\
90.15 \%\end{array}$ & $\begin{array}{l}\text { Adoptable in all } \\
\text { cases (only in one } \\
\text { case with } \\
\text { modifications) }\end{array}$ \\
\hline $\begin{array}{l}\text { Guidelines for the diagnosis } \\
\text { and management of syncope } \\
\text { (version 2009) } \\
\text { (National Guidelines } \\
\text { Clearinghouse) }\end{array}$ & $\begin{array}{l}180 / 198 \\
90.91 \%\end{array}$ & $\begin{array}{l}123 / 198 \\
62.12 \%\end{array}$ & $\begin{array}{c}433 / 528 \\
82 \%\end{array}$ & $\begin{array}{l}171 / 198 \\
86.36 \%\end{array}$ & $\begin{array}{l}187 / 264 \\
70.83 \%\end{array}$ & $\begin{array}{l}107 / 132 \\
75.76 \%\end{array}$ & $\begin{array}{c}\text { Adoptable in all } \\
\text { cases (in } 3 \text { case } \\
\text { with modifications) }\end{array}$ \\
\hline $\begin{array}{l}\text { Standardized Reporting } \\
\text { Guidelines for Emergency } \\
\text { Department Syncope Risk } \\
\text { Stratification Research } \\
\text { (NIH Public Access; Acad } \\
\text { Emerg Med 2013) } 34\end{array}$ & $\begin{array}{l}126 / 198 \\
63.64 \%\end{array}$ & $\begin{array}{l}123 / 198 \\
62.12 \%\end{array}$ & $\begin{array}{c}325 / 528 \\
61.55 \%\end{array}$ & $\begin{array}{l}130 / 198 \\
65.56 \%\end{array}$ & $\begin{array}{c}96 / 264 \\
36.36 \%\end{array}$ & $\begin{array}{l}107 / 132 \\
81.06 \%\end{array}$ & $\begin{array}{c}\text { Adoptable with } \\
\text { modifications } \\
\text { in } 8 / 11 \text {, unadoptable } \\
\text { in } 3 / 11 \text { cases }\end{array}$ \\
\hline $\begin{array}{l}\text { New Concepts in the Assessment } \\
\text { of Syncope (Brignole M, Hamda } \\
\text { MH, J Am Coll Cardiol 2012; } \\
1583-91)^{35}\end{array}$ & $\begin{array}{l}90 / 198 \\
a\end{array}$ & $\begin{array}{c}68 / 198 \\
34.34 \%\end{array}$ & $\begin{array}{l}124 / 528 \\
23.48 \%\end{array}$ & $\begin{array}{c}89 / 198 \\
44.94 \%\end{array}$ & $\begin{array}{l}117 / 264 \\
44.32 \%\end{array}$ & $\begin{array}{l}35 / 132 \\
26.52 \%\end{array}$ & $\begin{array}{l}\text { Adoptable with } \\
\text { modifications in } \\
5 / 11 \text {, unadoptable } \\
\text { in } 6 / 11 \text { cases }\end{array}$ \\
\hline $\begin{array}{l}\text { Transient loss of consciousness } \\
\text { (blackouts) in adults and young } \\
\text { people }(N I C E)^{1}\end{array}$ & $\begin{array}{c}187 / 198 \\
94.4 \%\end{array}$ & $\begin{array}{c}180 / 198 \\
90.9 \%\end{array}$ & $\begin{array}{c}441 / 528 \\
83.5 \%\end{array}$ & $\begin{array}{c}187 / 198 \\
94.4 \%\end{array}$ & $\begin{array}{l}226 / 264 \\
85.60 \%\end{array}$ & $\begin{array}{l}86 / 132 \\
65.15 \%\end{array}$ & $\begin{array}{l}\text { Adoptable in } 10 / 11 \\
\text { cases (only in one } \\
\text { case adoptable with } \\
\text { modifications) }\end{array}$ \\
\hline $\begin{array}{l}\text { The Emergency Department } \\
\text { Approach to Syncope: } \\
\text { Evidence-based Guidelines } \\
\text { and Prediction Rules } \\
\text { (Kessler C, Tristano JM, } \\
\text { De Lorenzo R, 2010) })^{37}\end{array}$ & $\begin{array}{l}178 / 198 \\
89.80 \%\end{array}$ & $\begin{array}{l}150 / 198 \\
75.76 \%\end{array}$ & $\begin{array}{c}253 / 528 \\
47.9 \%\end{array}$ & $\begin{array}{l}110 / 198 \\
55.55 \%\end{array}$ & $\begin{array}{c}82 / 264 \\
31.06 \%\end{array}$ & $\begin{array}{l}14 / 132 \mathrm{~L} \\
10.60 \%\end{array}$ & $\begin{array}{l}\text { Unadoptable in } 7 / 11 \text {, } \\
\text { adoptable in } 4 \\
\text { ( } 3 \text { with } \\
\text { modifications) }\end{array}$ \\
\hline $\begin{array}{l}\text { The } 2013 \text { ESC Guidelines on } \\
\text { cardiac pacing and cardiac } \\
\text { resynchronization therapy } \\
\text { [The Task Force on cardiac } \\
\text { pacing and resynchronization } \\
\text { therapy of the European Society } \\
\text { of Cardiology (ESC) in } \\
\text { collaboration with the European } \\
\text { Heart Rhythm Association (EHR }\end{array}$ & $\begin{array}{c}153 / 198 \\
77.27 \%\end{array}$ & $\begin{array}{l}133 / 198 \\
67.17 \%\end{array}$ & $\begin{array}{c}358 / 528 \\
67.80 \%\end{array}$ & $\begin{array}{l}182 / 198 \\
91.92 \%\end{array}$ & $\begin{array}{c}189 / 264 \\
71.59 \%\end{array}$ & $\begin{array}{l}124 / 132 \\
93.93 \%\end{array}$ & $\begin{array}{l}\text { Adoptable in } 10 / 11 \\
\text { (in } 6 \text { with } \\
\text { modifications) }\end{array}$ \\
\hline
\end{tabular}


Prediction Rules ${ }^{37}$ of 2010 was assessed unadoptable by $7 / 11$. The guideline achieved varying percentages score in various sizes: very high in the first $(89.80 \%)$ and very low in the fifth and especially in the sixth dimension (10.60\%).

The 2013 ESC Guidelines on cardiac pacing and cardiac resynchronization therapy ${ }^{18}$ was evaluated adoptable by evaluators $10 / 11$, albeit with changes in six cases; unadoptable in a single case. The guideline showed high percentage scores in the fourth and sixth dimension: respectively $91.92 \%$ and $93.93 \%$; too high the feedback obtained in the other dimensions, at around $70 \%$.

\section{Conclusions}

Understanding the pathophysiological cause of TLOC is crucial for reducing patients' morbidity and mortality. An accurate initial assessment based both on clinical/imaging findings and on a careful collection of medical history appropriately selects eligible patients to further more specific diagnostic strategies.

This monograph highlights the importance of establishing: i) if a syncope really occurred; ii) if it is cardiogenic or not; iii) if it requires further evaluation; and iv) which patients would benefit from intensive monitoring and hospitalization (Figure 4). ${ }^{38}$

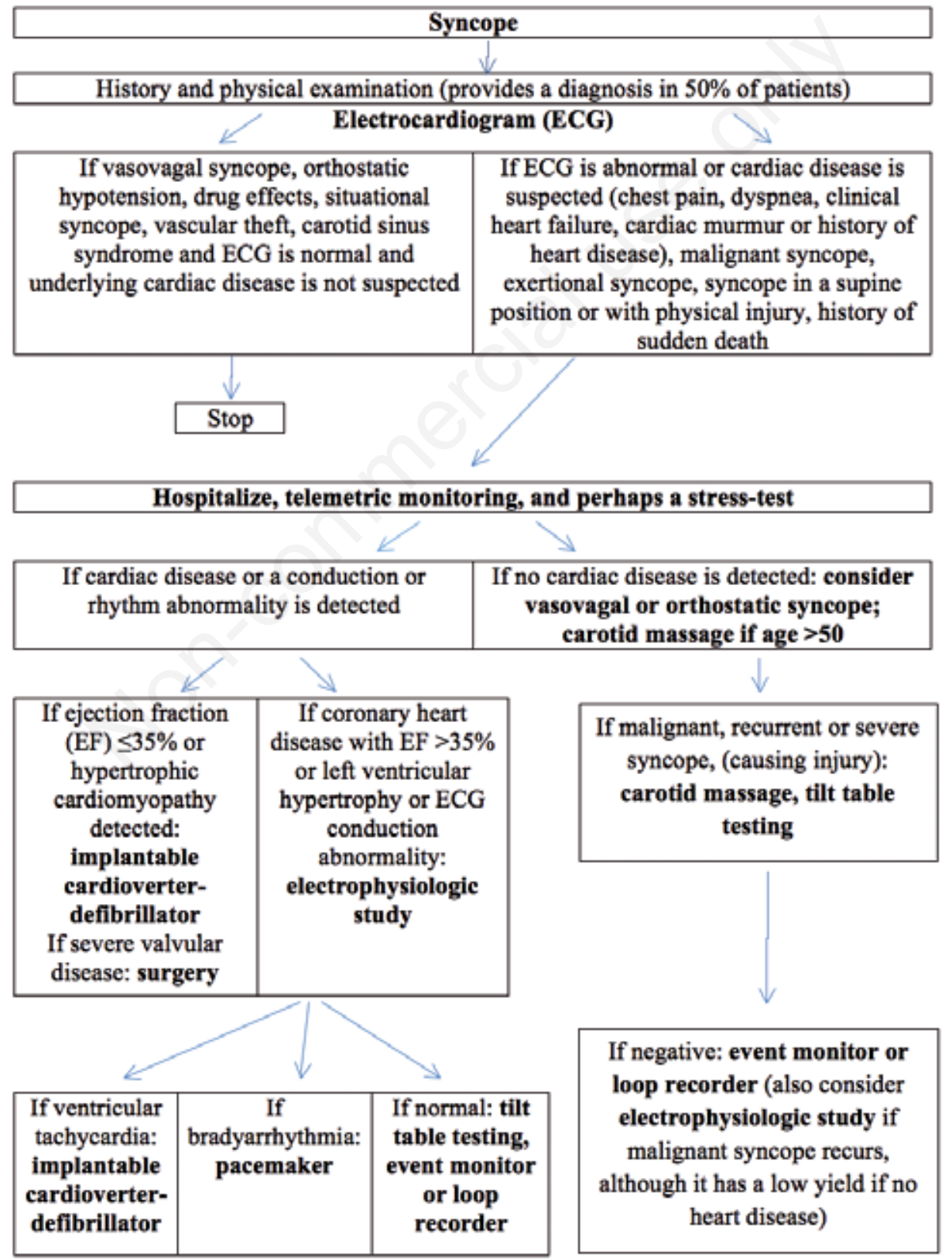

Figure 4. The management of syncope. Modified from Hanna, 2014. ${ }^{38}$ 


\section{References}

1. Rogers G. NICE guideline: transient loss of consciousness (blackouts) in adults and young people. Br J Gen Pract 2011;61:40-2.

2. The Task Force for the Diagnosis and Management of Syncope of the European Society of Cardiology (ESC). Guidelines for the diagnosis and management of syncope (version 2009). Eur Heart J 2009;30:2631-71.

3. Kenny RA, Bhangu J, King-Kallimanis BL. Epidemiology of Syncope/Collapse in younger and older western patient populations. Progr Cardiovasc Dis 2013;55:357-63.

4. Task Force for the Diagnosis and Management of Syncope; European Society of Cardiology (ESC); European Heart Rhythm Association (EHRA), et al. Guidelines for the diagnosis and management of syncope (version 2009). Eur Heart J 2009;30:2631-71.

5. Krediet CTP, Parry SW, Jardine DL, et al. The history of diagnosing carotid sinus hypersensitivity: why are the current criteria too sensitive? Europace 2011;13:14-22.

6. Iglesias JF, Graf D, Forclaz A. Stepwise evaluation of unexplained syncope in a large ambulatory population. Pacing Clin Electrophysiol 2009;32:S202-6.

7. Linker NJ, Voulgaraki D, Garutti C. Early versus delayed implantation of a loop recorder in patients with unexplained syncope-Effects on care patwhway and diagnostic yield. Intern J Card 2013;170:146-51.

8. Solano A, Menozzi C, Maggi R, et al. Incidence, diagnostic yield and safety of the implantable loop-recorder to detect the mechanism of syncope in patients with and without structural heart disease. Eur Heart J 2004;25:116-9.

9. Zaidi A, Clough P, Cooper P, Scheepers B. Misdiagnosis of epilepsy: many seizure-like attack have a cardiovascular cause. J Am Coll Cardiol 2000;36:181-4.

10. Rugg-Gunn F, Simister R, Squirrel M. Cardiac arrhythmias in focal epilepsy: a prospective long-term study. Lancet 2004;364:2212-9.

11. Armstrong L, Lawson J, Kamper A, Newton J. The use of implantable loop recorder in the investigation of unexplained syncope in older people. Age Ageing 2003;32: 185-8.

12. Edvardsson N, Frykman V, van Mechelen R, et al. Use of an implantable loop recorder to increase the diagnostic yield in unexplained syncope: results from the PICTURE registry. PICTURE Study Investigators. Europace 2011; 13:262-9.

13. Brignole M, Menozzi C, Moya A, et al. Pacemaker therapy in patients with neurally mediated syncope and documented asystole: Third International Study on Syncope of Uncertain Etiology (ISSUE-3): a randomized trial. Circulation 2012;125:2566-71.

14. Brignole M, Vardas P, Hoffman H. Indications for the use of diagnostic implantable and external ECG loop recorders. Euroapace 2009;11:671-87.

15. Kulakowski P, Lelonek M, Krynski T, Bacior B. Prospective evaluation of diagnostic workup in syncope patients: results of the PL-US registry. Europace 2010; 12:230-9.

16. Farwell DJ, Freemantle N, Sulke N. The clinical impact of implantable loop recorders in patients with syncope. Eur Heart J 2006;27:351-6.

17. Krahn AD, Klein GJ, Yee R, et al. Cost implications of testing strategy in patients with syncope: randomized assessment of syncope trial. J Am Coll Cardiol 2003;42: 495-501.

18. Brignole M, Auricchio A. 2013 ESC Guidelines on cardiac pacing and cardiac resynchronization therapy: The Task Force on cardiac pacing and resynchronization therapy of the European Society of Cardiology (ESC). Developed in collaboration with the European Heart Rhythm Association (EHRA). Eur Heart J 2013;34: 2281-329.

19. Claydon VE, Hainsworth R. Salt supplementation improves orthostatic cerebral and peripheral vascular control in patients with syncope. Hypertension 2004;43: 809-13.

20. van Lieshout JJ, ten Harkel AD, Wieling W. Physical manoeuvres for combating orthostatic dizziness in autonomic failure. Lancet 1992;339:897-8.

21. Podoleanu C, Maggi R, Brignole M, et al. Lower limb and abdominal compression bandages prevent progressive orthostatic hypotension in the elderly. A randomized placebo-controlled study. J Am Coll Cardiol 2006;48: 1425-32.

22. Smit AA, Wieling W, Fujimura J, et al. Use of lower abdominal compression to combat orthostatic hypotension in patients with autonomic dysfunction. Clin Auton Res 2004; 14:167-75.

23. Abraham WT, Fisher WG, Smith AL, et al. Cardiac resynchronization in chronic heart failure. N Engl J Med. 2002;346:1845-53.

24. Auricchio A, Stellbrink C, Butter C, et al. Clinical efficacy of cardiac resynchronization therapy using left ventricular pacing in heart failure patients stratified by severity of ventricular conduction delay. J Am Coll Cardiol 2003;42:2109-16.

25. Cazeau S, Leclercq C, Lavergne T, et al. Effects of multisite biventricular pacing in patients with heart failure and intraventricular conduction delay. N Engl J Med 2001;344:873-80.

26. Higgins SL, Hummel JD, Niazi IK, et al. Cardiac resynchronization therapy for the treatment of heart failure in patients with intraventricular conduction delay and malignant ventricular tachyarrhythmias. J Am Coll Cardiol 2003;42:1454-9.

27. Young JB, Abraham WT, Smith AL, et al. Combined cardiac resynchronization and implantable cardioversion defibrillation in advanced chronic heart failure: the MIRACLE ICD Trial. JAMA 2003;289:2685-94.

28. Moss AJ, Hall WJ, Cannom DS, et al. Cardiac-resynchronization therapy for the prevention of heart-failure events. N Engl J Med. 2009;361:1329-38.

29. Abraham WT, Young JB, Leon AR, et al. Effects of cardiac resynchronization on disease progression in patients with left ventricular systolic dysfunction, an indication for an implantable cardioverter-defibrillator, and mildly symptomatic chronic heart failure. Circulation 2004;110: 2864-8.

30. Linde C, Abraham WT, Gold MR, et al. Randomized trial of cardiac resynchronization in mildly symptomatic heart failure patients and in asymptomatic patients with left ventricular dysfunction and previous heart failure symptoms. J Am Coll Cardiol 2008;52:1834-43.

31. Tang AS, Wells GA, Talajic M, et al. Cardiac-resynchronization therapy for mild-to-moderate heart failure. $\mathrm{N}$ Engl J Med 2010;363:2385-95. 
32. Brouwers M, Kho ME, Browman GP, et al. AGREE II: Advancing guideline development, reporting and evaluation in healthcare. Can Med Assoc J 2010;182:E83942. [Italian version available from: http://www.gimbe. org/pagine/569/it/agree-ii]

33. Strickberger SA, Benson DW, Biaggioni I. AHA/ACCF Scientific Statement on the Evaluation of Syncope: From the American Heart Association Councils on Clinical Cardiology, Cardiovascular Nursing, Cardiovascular Disease in the Young, and Stroke, and the Quality of Care and Outcomes Research Interdisciplinary Working Group; and the American College of Cardiology Foundation: In Collaboration With the Heart Rhythm Society: Endorsed by the American Autonomic Society. Circulation 2006;113:316-27.

34. Benjamin C, Venkatesh T, Jeffrey DC. Standardized re- porting guidelines for emergency department syncope risk stratification research. NIH Public Access. Acad Emerg Med 2012;19:694-702.

35. Brignole M, Hamdan MH. New concepts in the assessment of syncope. J Am Coll Cardiol. 2012;59:1583-91.

36. Canadian Cardiovascular Society. Standardized approaches to the investigation of syncope: Canadian Cardiovascular Society position paper. Can J Cardiol 2011; 27:246-53.

37. Kessler C, Tristano JM, De Lorenzo R. The emergency department approach to syncope: evidence-based guidelines and prediction rules. Emerg Med Clin N Am 2010; 28:487-500.

38. Hanna EB. Syncope: etiology and diagnostic approach. Cleve Clin J Med 2014;8:755-66. 